\title{
Erratum: Counterion effects in cyanine heterojunction photovoltaic devices
}

\author{
FRANK NÜESCH
}

Swiss Federal Laboratories for Materials Testing and Research-EMPA, CH-8600 Dübendorf, Switzerland; Laboratoire d'optoélectronique des matériaux moléculaires, Institut des matériaux, EPFL, CH-1015 Lausanne, Switzerland

E-mail: frank.nueesch@empa.ch

ANTONIN FAES, LIBERO ZUPPIROLI

Laboratoire d'optoélectronique des matériaux moléculaires, Institut des matériaux, EPFL, CH-1015 Lausanne, Switzerland

FANSHUN MENG, KONGCHANG CHEN, HE TIAN

Institute of Fine Chemicals, East China University of Science \& Technology, Shanghai 200237, P. R. China

In Figure $3 b$ the current-voltage curve was plotted in an erroneous way. The corrected Figure is presented below:

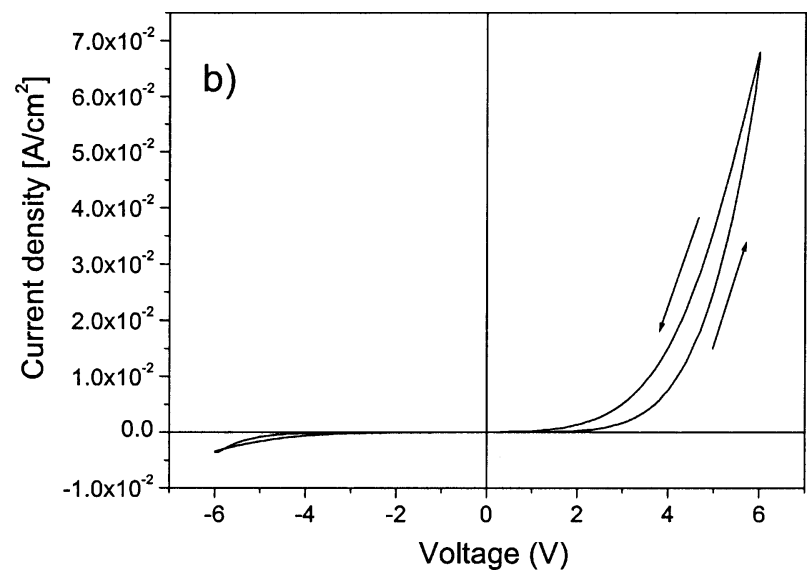

Figure $3 b$ Dark current-voltage characteristics of a device based on CY5 with free counterions.

At forward bias (positive bias applied to the ITO electrode) the current density is more important than at reverse bias (negative bias applied to the ITO electrode). The pronounced hysteretic behaviour depends on the sweep speed of the current-voltage scan and is attributed to slowly moving charges. Since the effect is only seen for cyanine layers having free counterions, we have attributed this behaviour to the perchlorate counterions accumulating at the PEDOT interface under forward bias. Similarly to an electrochemical device [23], this charge distribution reduces the energy barrier at the PEDOT/CY5 interface and strongly enhances hole injection. At reverse bias, the current-density is mainly limited by charge injection from both aluminium and PEDOT coated ITO electrodes, respectively. 